\title{
Fungsi Pengawasan dan Motivasi Kerja terhadap Kinerja Pegawai : Peran Tingkat Pendidikan Sebagai Pemoderasi
}

\author{
Muhammad Basyir $^{1 *}$, Sulaiman ${ }^{2}$ \\ 1,2 Fakultas Ekonomi dan Bisnis, Universitas Syiah Kuala, Kota Banda Aceh, \\ Provinsi Aceh, Indonesia.
}

\begin{abstract}
Abstrak. Penelitian ini menganalisis pengarub supervisi dan motivasi kerja terhadap kinerja pegawai negeri sipil dengan menetapkan tingkat pendidikan sebagai moderator dalam bubungan fungsional. Sampel penelitian ini adalah 250 pegawai negeri sipil yang bekerja di instansi pemerintah daerah kota Banda Aceh. Selanjutnya model statistik yang digunakan terdiri dari analisis regresi berganda dan regresi moderasi. Hasil penelitian menemukan bahwa kinerja pegawai negeri sipil dipengarubi secara positif oleh supervisi dan motivasi kerja. Tingkat pendidikan tidak hanya mempengarubi kinerja secara positif dan signifikan tetapi juga memoderasi bubungan motivasi kerja-kinerja. Namun tingkat pendidikan tidak memoderasi pengaruh supervisi terhadap kinerja PNS.
\end{abstract}

Kata kunci: Kinerja Pegawai Negeri Sipil; Pengawasan; Motivasi kerja; Tingkat Pendidikan; Analisis Regresi yang Dimoderasi.

\begin{abstract}
This study analyzes the effect of supervision and works motivation on civil servants' performance by assigning the education levels as a moderator in the functional relationship. The samples are 250 civil servants working in the local government agency of Banda Aceb city. Furthermore, the statistical model used consists of multiple regression and moderated regression analysis. The study discovered that civil servants' performance is positively affected by supervision and work motivation. The education level not only affects performance positively and significantly but also moderates the work motivation-performance relationship. However, education level does not moderate the effect of supervision on civil servants' performance.
\end{abstract}

Keywords: Civil Servants' Performance; Supervision; Work Motivation; Education Level; Moderated Regression Analysis. 


\section{Pendahuluan}

Pegawai merupakan sumber daya utama setiap organisasi, termasuk organisasi publik seperti halnya instansi pemerintah. Keberadaan pegawai dan kemampuan kerja yang mereka miliki sangat menentukan keberhasilan penyelenggaraan layanan publik. Bahkan sejumlah kajian membuktikan bahwa kinerja pegawai merupakan determinan utama keberhasilan instansi pemerintah dalam melayani masyarakat. Karena itu, upaya peningkatan kinerja pegawai menjadi sutau keharusan. Namun, dalam tataran empiris, kinerja pegawai pada setiap instansi pemerintah tidak sama. Seperti halnya kinerja pegawai dilingkungan pemerintah kota Banda Aceh, hasil survei awal dengan menjadikan sejumlah pegawai sebagai informan mengindikasikan bahwa tidak semua pegawai memiliki kinerja sesuai dengan yang diharapkan instansi. Sebagian pegawai justru memiliki kinerja rendah, dan kondisi ini menjadi tantangan bagi instansi terkait dalam meningkatkan kualitas pelayanan publik.

Secara teoritis, sejumlah kajian mengkaitkan kinerja pegawai dengan faktor internal dan eksternal pegawai (Uddin et al., 2013; Ahmed \& Ahmed, 2014). Faktor internal yang mempengaruhi kinerja pegawai diantaranya adalah motivasi kerja (Chong \& Van, 2013; \& Shahzadi et al., 2014) dan kepuasan kerja (Chong \& Van, 2013; Fadlallh, 2014). Selain itu, pendidikan pegawai juga merupakan faktor internal yang dapat berdampak pada kinerja mereka dalam melanjalankan tugas $(\mathrm{Ng} \&$ Feldman, 2009; Awang et al., 2010; González et., al. 2016). Selanjutnya faktor eksternal yang mempengaruhi kinerja pegawai di antaranya adalah lingkungan kerja (Srivastava, 2008); kepemimpinan (Bello, 2014); dan pengawasan (Situmeang, 2017; Syamsidar \& Hasyim, 2018).

Kinerja pegawai negeri sipil (PNS) dilingkungan pemerintah kota Banda Aceh kiranya juga dapat diprediksi dengan menggunakan faktor internal dan eksternal pegawai. Faktor internal yang dimaksudkan dalam kajian ini adalah motivasi kerja dan tingkat pendidikan. Selanjutnya faktor eksternal yang dimaksudkan adalah pengawasan. Hasil survei awal mengindikasikan bahwa para pegawai dilingkungan pemerintah kota tersebut memiliki motivasi kerja yang berbeda. Selain itu, penilaian mereka terhadap pengawasan ditempat kerja juga berbeda. Sehingga kepedulian mereka terhadap upaya peningkatan kualitas dan kuantitas hasil kerja juga berbeda. Dalam hal latar belakang pendidikan, pegawai dilingkungan pemerintah tersebut memiliki latar belakang pendidikan berbeda. Bahkan sebagian diantara mereka tidak memiliki latar belakang pendidikan tinggi. Karena itu, kajian mengenai kinerja pegawai dalam kaitannya dengan motivasi kerja, pengawasan dan tingkat pendidikan menjadi penting untuk dilakukan.

Penelitian ini menempatkan tingkat pendidikan sebagai moderating variable antara motivasi kerja dan pengawasan dengan kinerja pegawai. Sehingga temuan penelitian tidak hanya mampu memberikan bukti empiris tentang arah dan signifikansi pengaruh motivasi dan pengawasan terhadap kinerja, tetapi juga dapat menyajikan bukti statistik tentang pengaruh kedua predictor variable tersebut berdasarkan latar belakang pendidikan pegawai. Penggunaan moderated regression analysis (MRA) sebagai model analisis data mampu memberikan bukti statistik dimaksud.

\section{Tinjauan Literatur}

\section{Keterkaitan Motivasi Kerja dan Kinerja pegawai}

Adanya keterkaitan antara motivasi kerja terhadap kinerja seperti dikemukakan oleh Mangkuprawira (2013:117) bahwa faktor-faktor yang mempengaruhi kinerja karyawan relatif kompleks termasuk faktor instrinsik atau faktor yang berasal dari dalam diri karyawan itu sendiri termasuk motivasi kerja. Selain bersumber dari dalam diri sendiri, kekuatan motivasi kerja seseorang juga dapat berasal dari lingkungan. Nilai-nilai dan norma-norma yang dianut oleh lingkungan sosial tempat seseorang bekerja dapat mendorong munculnya motivasi kerja dan pada gilirannya berdampak pada kinerja (Fathoni, 2016:132).

Peran penting motivasi kerja dalam mendorong pembentukan kinerja juga dinyatakan oleh Uno (2007:71) bahwa motivasi kerja determinan penting kinerja seseorang pegawai. Kekuatan motivasi pada diri seseorang ditentukan oleh 
seberapa besar intensitas motivasi yang dirasakannya, dan capaian kinerja atau prestasi kerja yang mampu diraihnya dapat dijadikan refleksi motivasi kerja orang tersebut (Fathoni (2016:132).

\section{Keterkaitan pengawasan dan kinerja pegawai}

Dalam rangka meningkatkan kinerja layanan pendidikan di perguruan tinggi diperlukan adanya pegawasan. Pengawasan tersebut dimaksudkan untuk memastikan agar kegiatan yang dilakukan oleh tenaga bidang kependidikan dapat berjalan sebagaimana mestinya. Pentingnya pengawasan dalam upaya pencapaian kinerja baik kinreja organisasi maupun individu telah dibuktikan oleh sejumlah peneliti. Seperti halnya penelitian Averus \& Pitono (2018) membuktikan bahwa pengawasan berpengaruh positif dan signifikan terhadap kinerja pegawai dalam memberikan pelayanan kepada masyarakat. Penelitian Situmeang (2017) dan Syamsidar \& Hasyim (2018) juga memberikan bukti yang sama, dimana pengawasan secara nyata berdampak positif terhadap kinerja karyawan.

\section{Keterkaitan Pendidikan dan Kinerja Pegawai}

Peran pendidikan dalam mendorong peningkatan kinerja seseorang individu telah menjadi sorotan para peneliti manajemen sumber daya manusia. Umumnya mereka menemukan bahwa tingkat pendidikan menjadi syarat penting bagi kinerja individu. Hal ini disebabkan, tingkat pendidikan yang dicapai oleh seseorang tidak hanya menjadi determinan utama keterampilan dan kemampuan kerja, tetapi juga berdampak pada pembentukan sikap kerja yang pada gilirannya berkontribusi besar bagi kemampuan menyelesaikan pekerjaan. Tingkat pendidikan berkontribusi penting dalam meningkatkan kinerja karyawan $(\mathrm{Ng}$ \& Feldman, 2009). Karyawan dengan tingkat pendidikan relatif tinggi akan memiliki kemampuan kerja yang jauh lebih baik dibanidngkan dengan karyawan berpendidikan rendah (Awang et al., 2010; González et., al. 2016). Kajian empiris yang dilakukan oleh Double et al. (2019) juga menggarisbawahi pentingnya tingkat pendidikan dalam meningkatkan kinerja karyawan.

\section{Peran moderasi tingkat pendidikan terhadap hubungan antara kinerja pegawai dengan motivasi kerja dan pengawasan}

Adanya peran moderasi tingkat pendidikan dalam mengintervensi pengaruh motivasi kerja terhadap kinerja karyawan didukung oleh sejumlah penelitian. Seperti halnya penelitian Orpen (1994) yang menemukan bahwa tingkat pendidikan mengintervensi pengaruh motivasi kerja dan pengawasan personal terhadap kinerja karyawan. Dalam skala makro, tingkat pendidikan juga memoderasi pengaruh status karyawan (bekerja atau tidak bekerja) terhadap munculnya inspirasi mencari pekerjaan (Capelleras et al., 2016). Penelitian Lee \& Hallak (2018) dalam kajian mereka pada perusahaan jasa makanan juga membuktikan bahwa tingkat pendidikan memoderasi pengaruh tingkat pendidikan terhadap kinerja karyawan. Temuan ini juga didukung oleh hasil kajian Chang (2019) tentang kinerja perusahaan, bahwa tingkat pendidikan tidak hanya memoderasi pengaruh motivasi kerja terhadap kinerja karyawan, tetapi juga moderasi pengaruh motivasi kerja karyawan terhadap kinerja perusahaan. Adanya peran tingkat pendidikan dalam memoderasi pengaruh pengawasan terhadap kinerja karyawan didukung oleh sejumlah peneliti sebelumnya. Penelitian Moser \& Galais (2007) memberikan bukti empiris bahwa tingkat pendidikan moderasi pengaruh pengawasan terhadap kinerja karyawan. Penelitian lain yang dilakukan oleh Schjoedt \& Sangboon (2015), Sihag \& Rijsdijk (2018) dan Remus et al. (2020) juga menyimpulkan bahwa tingkat pendidikan mempengaruhi dampak pengawasan terhadap kinerja karyawan.

\section{Metodologi Penelitian}

Fokus penelitian hanya menganalisis hubungan fungsional antara kinerja pegawai dengan motivasi kerja dan pengawasan serta peran tingkat pendidikan dalam hubungan fungsional tersebut. Penelitian dilakukan terhadap pegawai dilingkungan pemerintahan kota Banda Aceh yang tersebar pada sejumlah SKPK. Sampel penelitian sebanyak 250 orang pegawai yang dipilih secara purposive random sampling. Pengumpulan data dilakukan dengan cara mengedarkan kuesioner pada pegawai di setiap SKPK. 
Sesuai dengan batasan variabel, penelitian ini mengoperasionalkan empat variabel, terdiri dari kinerja karyawan, motivasi kerja, pengawasan dan tingkat pendidikan. Kinerja karyawan merefleksikan hasil kerja yang dicapai karyawan dalam melaksanakan beban kerja yang ditugaskan. Pengukuran variabel ini menggunakan lima indikator penting terdiri dari kualitas kerja, kuantitas (hasil kerja), ketepatan waktu, kemandirian dalam bekerja dan komitmen pegawai dalam melaksanakan tugas. Motivasi kerja merefleksikan kesediaan seseorang dalam mengarahkan kemauan, keahlian serta keterampilan kerja yang dimiliki dalam melaksanakan tugas (Segal, 2010:26). Pengukuran motivasi kerja menggunakan tujuh indikator meliputi keinginan untuk bekerja, memperbaiki hasil kerja dan melaksanakan tugas secara baik, kemauan mencapai target kerja dan keberhasilan menjalankan tugas, tidak mudah putus asah ketika dihadapkan pada pekerjaan sulit dan tidak mudah jenuh dalam melaksanakan tugas rutin (Amri, 2015). Selanjutnya, fungsi pengawasan merupakan proses pekerjaan guna memastikan realisasi pelaksanaan tugas oleh pegawai tidak menyimpang dari standar dan target yang telah ditetapkan. Pengukuran variabel ini menggunakan sejumlah indikator terdiri dari, adanya pengawasan dalam bekerja, kejelasan standar kerja, adanya penilaian dan evaluasi terhadap capaian pekerjaan, dan tersedianya prosedur kerja yang jelas sehingga memungkinkan dilakukan perbaikan.

Masing-masing indikator yang digunakan dalam mengukur tiga variabel di atas dijabarkan dalam bentuk pernyataan positif. Setiap pernyataan disediakan alternatif pilihan jawaban dalam bentuk kesetujuan (setuju tidak setuju). Penilaian pegawai terhadap suatu variabel didasarkan pada alternatif pilihan jawaban yang mereka berikan pada pernyataan terkait (Amri, 2013; Ratnawati \& Amri, 2013; Iskandar \& Amri, 2014). Masing-masing pilihan tingkat kesetujuan kemudian diberikan skor berdasarkan skala Likert 1 sampai 5 . Selanjutnya tingkat pendidikan mengacu pada latar belakang pendidikan (terakhir) pegawai. Variabel ini tidak hanya digunakan sebagai predictor variables bagi kinerja pegawai, tetapi juga diposisikan sebagai moderating variable antara kinerja pegawai di satu sisi dengan motivasi kerja dan pengawasan di sisi lain. Tingkat pendidikan dikelompokkan dalam dua kelompok yakni pendidikan tinggi dan bukan pendidikan tinggi. Pengukuran variabel ini menggunakan skala katagori dengan ketentuan, pendidikan tinggi diberikan skor 1 , dan bukan pendidikan tinggi diberikan skor 0 .

Guna mendapatkan koefisien estimasi masingmasing predictor variables serta mengetahui efek moderasi tingkat pendidikan dalam hubungan fungsional antara kinerja pegawai dengan motivasi kerja dan pengawasan, penelitian ini menggunakan moderated regression analysis (MRA). Dalam praktiknya penggunaan MRA terdiri dari beberapa tahapan proses regresi seperti ditunjukkan dalam persamaan 1, 2 dan 3.

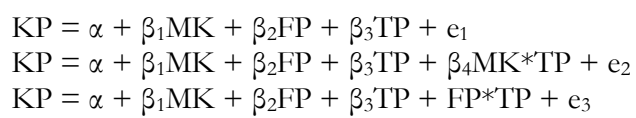

Dimana, KP adalah kinerja pegawai, MK adalah motivasi kerja, FP adalah fungsi pengawasan, TP adalah tingkat pendidikan, dan selanjutnya $\alpha$ dan $\beta$ masing-masing adalah konstanta dan koefisien estimasi. MK*TP adalah interaksi antara motivasi kerja dan tingkat pendidikan, dan terakhir FP*TP adalah interaksi antara pengawasan dan tingkat pendidikan. Terakhir, $\mathrm{e}_{1}, \mathrm{e}_{2}$, dan $\mathrm{e}_{3}$ masing-masing persamaan.

Pengujian efek moderasi tingkat pendidikan dalam pengaruh motivasi kerja terhadap kinerja pegawai (persamaan 2) didasarkan pada pendapat Entrialgo \& Iglesias (2016) yang menyatakan bahwa keberadaan efek moderasi dapat dideteksi dengan cara membandingkan signifikansi koefisien estimasi antar variabel. Koefisien estimasi yang diperbandingkan adalah koefisien estimasi variabel eksogen (yang dimoderasi) dengan koefisien estimasi variabel moderasi itu sendiri (Fairchild \& McQuillin, 2010; Boudreaux et al., 2018; Muliadi \& Amri, 2019). Mengadopsi kedua pendapat tersebut, maka deteksi terhadap efek moderasi tingkat pendidikan dalam persamaan 2 didasarkan pada signifikansi nilai koefisien estimasi motivasi kerja $\left(\beta_{1}\right)$ dan nilai koefisien estimasi variabel pemoderasi $\left(\beta_{3}\right)$ dengan ketentuan jika $\beta_{1}$ tidak signifikan ( $p$-value $>0,05)$ dan $\beta_{3}$ signifikan $(\phi-$ value $<0,05)$, maka tingkat pendidikan dikatakan 
memiliki efek moderasi murni (pure moderating). Sementara itu, jika $\beta_{1}$ dan $\beta_{3}$ keduanya adalah signifikan ( $p$-value $<0,05$ ), variabel tingkat pendidikan dikatakan memiliki efek quasi moderasi. Selanjutnya, jika $\beta_{1}$ signifikan ( $p$-value $<0,05)$, dan $\beta_{3}$ tidak signifikan ( $p$-value $\left.>0,05\right)$, variabel tingkat pendidikan hanya dianggap sebagai variabel independen tetapi tidak berperan sebagai variabel moderasi. Ketentuan yang sama juga berlaku untuk persamaan 3 yang menjelaskan eksistensi tingkat pendidikan dalam memoderasi pengaruh fungsi pengawasan terhadap kinerja karyawan. Pengujian efek moderasi didasarkan pada signifikansi nilai koefisien estimasi fungsi pengawasan $\left(\beta_{2}\right)$ dengan nilai koefisien estimasi variabel pemoderasi $\left(\beta_{3}\right)$ dengan ketentuan jika $\beta_{2}$ tidak signifikan $(p$-value $>0,05)$ dan $\beta_{3}$ signifikan ( $p$-value $<0,05)$, maka tingkat pendidikan dikatakan memiliki efek moderasi murni (pure moderating). Sementara itu, jika $\beta_{2}$ dan $\beta_{3}$ keduanya adalah signifikan ( $p$-value $<$ $0,05)$, variabel tingkat pendidikan dikatakan memiliki efek quasi moderasi. Selanjutnya, jika $\beta_{2}$ signifikan ( $p$-value $\left.<0,05\right)$, dan $\beta_{3}$ tidak signifikan ( $\not$-value $>0,05$ ), variabel tingkat pendidikan hanya dianggap sebagai variabel independen tetapi tidak berperan sebagai variabel moderasi.

\section{Hasil dan Pembahasan}

\section{Statistik Deskriptif}

Pegawai yang menjadi sampel penelitian ini terdiri dari dua kelompok, yakni pegawai dengan latar belakang pendidikan tinggi, dan bukan pendidikan tinggi. Sebagian besar di antara mereka adalah lulusan perguruan tinggi 145 orang $(66 \%)$. Dengan demikian, pegawai dengan latar belakang bukan pendidikan tinggi hanya 105 orang $(34 \%)$. Untuk lebih jelasnya mengenai frekuensi pegawai berdasarkan latar belang pendidikan seperi dalam Tabel 1 .

Tabel 1. Pegawai Berdasarkan Latar Belakang Pendidikan

\begin{tabular}{|l|c|c|}
\hline \multicolumn{1}{|c|}{ Pendidikan } & $\begin{array}{c}\text { Frekuensi } \\
\text { (Orang) }\end{array}$ & $\begin{array}{c}\text { Persentase } \\
(\%)\end{array}$ \\
\hline Pendidikan Tinggi & 165 & 66 \\
\hline $\begin{array}{l}\text { Bukan Pendidikan } \\
\text { Tinggi }\end{array}$ & 85 & 34 \\
\hline & 250 & 100,00 \\
\hline
\end{tabular}

Sumber: Data Primer (Diolah), 2021
Pengaruh motivasi kerja dan pengawasan terhadap kinerja karyawan dapat dimoderasi oleh tingkat pendidikan. Sejumlah penelitian juga memberikan bukti empiris tentang peran tingkat pendidikan dalam memoderasi pengaruh antar variabel dalam kajian manajemen sumber daya manusia (Moser \& Galais, 2007; Capelleras et al. 2016). Berkaitan dengan kajian terhadap kinerja pegawai dilingkungan pemerintah kota Banda Aceh, analisis peran moderasi tingkat pendidikan dalam hubungan fungsional antara kinerja di satu sisi dengan motivasi kerja dan pengawasan di sisi lain menggunakan moderated regression analysis (MRA). MRA yang berkaitan dengan efek moderasi tingkat pendidikan terhadap hubungan fungsional antara kinerja karyawan dengan motivasi kerja pegawai dan pengawasan seperti ditunjukkan dalam Tabel 1.

Tabel 2. Hasil Moderated Regression Analysis

\begin{tabular}{|c|c|c|c|}
\hline & Model 1 & Model 2 & Model 3 \\
\hline Const $(\alpha)$ & $\begin{array}{c}-1,302 \\
{[-4,031]} \\
(0,000)\end{array}$ & $\begin{array}{c}-5,171 \\
{[-4,281]} \\
(0,000)\end{array}$ & $\begin{array}{c}-1,595 \\
{[-1,942]} \\
(0,057)\end{array}$ \\
\hline $\operatorname{MK}\left(\beta_{1}\right)$ & $\begin{array}{c}0,740 \\
{[8,432]} \\
(0,000)\end{array}$ & $\begin{array}{c}0,844 \\
{[9,382]} \\
(0,000)\end{array}$ & $\begin{array}{c}0,733 \\
{[8,135]} \\
(0,000)\end{array}$ \\
\hline $\operatorname{FP}\left(\beta_{2}\right)$ & $\begin{array}{c}0,388 \\
{[6,062]} \\
(0,000)\end{array}$ & $\begin{array}{c}0,347 \\
{[5,530]} \\
(0,000)\end{array}$ & $\begin{array}{c}0,399 \\
{[5,676]} \\
(0,000)\end{array}$ \\
\hline $\operatorname{PDK}\left(\beta_{3}\right)$ & $\begin{array}{c}0,572 \\
{[8,121]} \\
(0,000)\end{array}$ & $\begin{array}{c}4,216 \\
{[3,901]} \\
(0,000)\end{array}$ & $\begin{array}{c}0,852 \\
{[1,181]} \\
(0,241)\end{array}$ \\
\hline $\mathrm{MK} * \operatorname{PDK}\left(\beta_{4}\right)$ & - & $\begin{array}{c}-0,928 \\
{[-3,311]} \\
(0,001)\end{array}$ & $(0,-1-1)$ \\
\hline $\mathrm{FP} * \operatorname{PDK}\left(\beta_{4}\right)$ & - & - & $\begin{array}{c}-0,072 \\
{[-0,389]} \\
(0,698)\end{array}$ \\
\hline $\mathrm{R}^{2}$ & 0,858 & 0,871 & 0,858 \\
\hline Adj-R ${ }^{2}$ & 0,733 & 0,756 & 0,738 \\
\hline F-hitung & 108,623 & 90,968 & 80,906 \\
\hline $\begin{array}{l}\text { F-hit } \quad(\mathrm{P}- \\
\text { value })\end{array}$ & 0,000 & 0,000 & 0,000 \\
\hline
\end{tabular}

Sumber: Data Primer (Diolah), 2021.

Catatan: Angka dalam tanda [ ] adalah nilai t statistik; ( ) adalah nilai $\mathrm{p}$-value; $\mathrm{p}$ value $<0,05$ mengindikasikan signifikan pada keyakinan $95 \%$;

Tabel 2 di atas merupakan ringkasan dari tiga tahapan regresi. Model pertama merepresentasikan hubungan fungsional antara 
kinerja pegawai dengan tiga predictor variable terdiri dari motivasi kerja, pengawasan dan tingkat pendidikan. Ketiga variabel tersebut berpengaruh positif dan signifikan terhadap kinerja pegawai. Artinya, semakin tinggi motivasi kerja, semakin baik fungsi pengawasan dan semakin tinggi tingkat pendidikan, maka semakin baik kinerja pegawai. Sebaliknya, penurunan motivasi kerja dan pengawasan serta tingkat pendidikan yang rendah berdampak pada penurunan kinerja pegawai.

Model 2 merupakan MRA untuk menganalisis keberadaan tingkat pendidikan dalam memoderasi pengaruh motivasi kerja terhadap kinerja pegawai. Seperti dalam tabel 2, koefisien estimasi motivasi kerja terhadap kinerja adalah signifikan dengan nilai p-value sebesar 0,000. Selanjutnya koefisien estimasi moderating variabel (interaksi antara motivasi kerja dan tingkat pendidikan) juga signifikan dengan nilai $p$-value sebesar 0,001. Hal ini berarti bahwa tingkat pendidikan memoderasi pengaruh motivasi kerja terhadap kinerja pegawai. Dengan kata lain, tingkat pendidikan berdampak signifikan pada pengaruh motivasi kerja terhadap kinerja pegawai.

Selanjutnya model 3 merupakan ringkasan MRA untuk menguji eksistensi peran tingkat pendidikan pada pengaruh fungsi pengawasan terhadap kinerja pegawai. Koefisien estimasi fungsi pengawasan adalah signifikan dengan nilai p-value sebesar 0,000 . Selanjutnya koefisien estimasi moderating variabel (interaksi antara pengawasan dan tingkat pendidikan) tidak signifikan dengan nilai p-value sebesar 0,698. Hal ini berarti bahwa tingkat pendidikan bukanlah variabel pemoderasi, tetapi hanya berperan sebagai variabel independen. Temuan ini bertolak belakang dengan hasil penelitian Moser \& Galais (2007) yang membuktikan adanya peran moderasi tingkat pendidikan terhadap pengaruh pengawasan terhadap kinerja karyawan. Temuan ini juga tidak sejalan dengan hasil kajian Schjoedt \& Sangboon (2015), Sihag \& Rijsdijk (2018) dan Remus et al. (2020) juga menyimpulkan bahwa tingkat pendidikan mempengaruhi dampak pengawasan terhadap kinerja karyawan.

Implikasi teoritis berkaitan dengan implikasi kajian yang dikaitkan dengan landasan teoritis dan kajian empiris sebelumnya. Adanya pengaruh positif dan signifikan motivasi kerja terhadap kinerja pegawai mendukung pendapat Muslim et al. (2016) yang menyatakan bahwa motivasi kerja merupakan faktor penting dalam mendorong keinginan pegawai untuk bekerja secara baik. Secara umum motivasi kerja yang tinggi berhubungan positif dengan hasil kerja pegawai. Temuan ini penelitian ini sejalan dengan hasil kajian sejumlah peneliti sebelumnya seperti Curtis et al. (2009), Robescu \& Iancu (2016), Turner (2017) dan Van der Kolk et al. (2018) yang juga mememukan bahwa motivasi kerja berpengaruh terhadap kinerja karyawan. Temuan ini juga mendukung temuan penelitian sebelumnya yang dilakukan oleh Chien et al. (2020) yang juga membuktikan adanya pengaruh motivasi kerja terhadap kinerja karyawan. Penelitian ini juga membuktikan bahwa fungsi pengawasan berpengaruh positif dan signifikan terhadap kinerja pegawai. Hasil ini sesuai dengan pendapat Mor Barak et al. (2009) yang menyatakan bahwa pengawasan memiliki peran penting dalam upaya meningkatkan kinerja individual. Temuan ini konsisten temuan penelitian Kadarisman (2019) terhadap pegawai negeri sipil di Indonesia juga menemukan bukti empiris bahwa pengawasan berdampak positif terhadap kinerja pegawai. Temuan ini juga memperkuat hasil penelitian Sihag \& Rijsdijk (2018) dan penelitian Lee et al. (2018) yang juga menyimpulkan bahwa pengawasan secara nyata meningkatkan kinerja pegawai.

\section{Kesimpulan dan Rekomendasi}

Fungsi pengwasan dan motivasi kerja berpengaruh positif dan signifikan terhadap kinerja pegawai dilingkungan pemerintah kota Banda Aceh. Semakin fungsi pengawasan dan motivasi kerja pegawai semakin tinggi pula kinerja pegawai. Sebaliknya, ketika fungsi pengawasan kurang baik, dan motivasi kerja pegawai rendah, maka kinerja pegawai akan rendah. Tingkat pendidikan dapat mendorong peningkatan kinerja pegawai. Pegawai dengan latar belakang pendidikan tinggi memiliki kinerja relatif lebih baik dibandingkan dengan mereka yang berlatar belakang pendidikan bukan pendidikan tinggi. 
Keberadaan latar belakang pendidikan memoderasi pengaruh motivasi kerja terhadap kinerja pegawai. Dengan kata lain, pengaruh motivasi kerja terhadap kinerja pegawai berbeda berdasarkan katagori tingkat pendidikan. Efek moderasi tersebut adalah positif yang berarti, pengaruh motivasi kerja terhadap kinerja pegawai lebih besar pada pegawai yang memiliki latar belakang pendidikan tinggi. Sebaliknya, pada pegawai dengan pendidikan bukan perguruan tinggi, pengaruh tersebut lebih kecil. Sebaliknya, latar belakang pendidikan tidak memoderasi pengaruh fungsi pengawasan terhadap kinerja pegawai. Artinya, pengaruh fungsi pengawasan terhadap kinerja tidak berbeda berdasarkan kelompok pendidikan pegawai. Meskipun fungsi pengawasan secara positif berpengaruh terhadap kinerja pegawai, namun pengaruh tersebut tidak berbeda menurut katagori latar belakang pendidikan pegawai.

Mengacu pada kesimpulan di atas, maka upaya peningkatan kinerja pegawai dilingkungan pemerintah kota Banda Aceh, tidak hanya dapat dilakukan dengan meningkatkan motivasi kerja pegawai tetapi juga mendorong terlaksananya fungsi pengawasan secara baik. Lebih penting dari itu, pemerintah kota ini perlu mendorong pegawainya untuk dapat melanjutkan pendidikan ke perguruan tinggi. Pemberian izin belajar bagi pegawai agar dapat melanjutkan studi ke perguruan tinggi sesuai dengan bidang penempatan kerja mereka merupakan langkah strategis yang perlu dipertimbangkan guna meningkatkan kinerja mereka dalam melaksanakan tugas.

\section{Daftar Pustaka}

Ahmed, M., \& Ahmed, A. B. (2014). The Impact of Indirect Compensation on Employee performance: An Overview, Public Policy and Administration Research, 4(6), 27-31.

Amri, K. (2013). Faktor-faktor yang mempengaruhi loyalitas konsumen surat kabar Harian Serambi Indonesia di kota Banda Aceh. Jurnal Ekonomi Manajemen dan Bisnis, 1(1), 229-242.
Amri, K. (2015). Pengaruh perilaku kepemimpinan dan motivasi kerja dalam meningkatkan produktivitas kerja karyawan PT Bank Sinarmas Tbk cabang Banda Aceh. Jurnal Ekonomi Manajemen dan Bisnis, 3(1), 522-536.

Averus, A., \& Pitono, A. (2018). Pengaruh Pengawasan Terhadap Kinerja Pegawai Dalam Meningkatkan Pelayanan Kesehatan di kota Palu Provinsi Sulawesi Tengah, Sosiobumaniora - Jurnal Ilmu-ilmu Sosial dan Humaniora, 20(1), 15 - 21

Awang, A. H., Ismail, R., \& Mohd Noor, Z. (2010). Training Impact on Employee'S Job Performance: A Self Evaluation. Economic Research-Ekonomska Istrą̌ivanja, 23(4), 78-90. doi:10.1080/1331677x.2010.11517434

Bello, M. S. (2014). Impact of Ethical Leadership on Employee Job Performance, International Journal of Business and Social Science, 3(11) 228-236.

Boudreaux, C. J., Nikolaev, B. N., \& Klein, P. (2018). Socio-cognitive traits and entrepreneurship: The moderating role of economic institutions. Journal of Business Venturing. doi:10.1016/j.jbusvent. 2018.08.003.

Capelleras, J.-L., Contín-Pilart, I., LarrazaKintana, M., \& Martin-Sanchez, V. (2016). Unemployment and Growth Aspirations: The Moderating Role of Education. Strategic Change, 25(2), 171-185. doi:10.1002/jsc.2054

Chang, Y.-S. (2019). Bonding Ties, Bridging Ties, and Firm Performance: The Moderating Role of Dynamic Capabilities in Networks. Journal of Business-to-Business Marketing, $1-18$. doi:10.1080/1051712x.2019.1603395

Chong, N. N., dan Dung, N. V. (2013) Effects of Motivation and Job satisfaction on Employees' Performance at Petrovietnam Nghean Construction Joints Stock Corporation (PVNC), International Journal of Business and Social Science, 4(6), 215-226. 
Curtis, C. R., Upchurch, R. S., \& Severt, D. E. (2009). Employee Motivation and Organizational Commitment: A Comparison of Tipped and Nontipped Restaurant Employees. International Journal of Hospitality \& Tourism Administration, $\quad 10(3), \quad 253$ 269. doi:10.1080/15256480903088469

Double, K. S., McGrane, J. A., \& Hopfenbeck, T. N. (2019). The Impact of Peer Assessment on Academic Performance: A Meta-analysis of Control Group Studies. Educational Psychology Review. doi:10.1007/s10648-019-09510-3

Entrialgo, M., \& Iglesias, V. (2016). The moderating role of entrepreneurship education on the antecedents of entrepreneurial intention, International Enterpreneurship Management Journal, doi: 10.1007/s11365-016-0389-4

Fadlallh, A. W. (2014). Impact of Job Satisfaction on Employees Performance an Application on Faculty of Science and Humanity Studies University of Salman Bin Abdul-Aziz-Al Aflaj, International Journal of Innovation and Research in Educational Sciences, 2(1), 26-31.

Fairchild, A. J., \& McQuillin, S. D. (2010). Evaluating mediation and moderation effects in school psychology: A presentation of methods and review of current practice. J Sch Psychol, 48(1); 5384. doi:10.1016/j.jsp.2009.09.001.

Farnita, I., \& Amri, K. (2013). Persepsi mahasiswa terhadap kualitas layanan pendidikan Akademi Manajemen Informatika dan Komputer Indonesia (AMIKI), Banda Aceh. Jurnal Ekonomi Manajemen dan Bisnis 1 (1), 118-139.

Fathoni, A. (2016). Organisasi dan Manajemen Sumber Daya Manusia, Rineka Cipta, Jakarta.
González, F., Sánchez, S. M., \& LópezGuzmán, T. (2016). The Effect of Educational Level on Job Satisfaction and Organizational Commitment: A Case Study in Hospitality. International Journal of Hospitality \& Tourism Administration, 17(3), 243-259. doi:10.1080/15256480.2016.1183547

Iskandar, D., \& Amri, K. (2014). Pengaruh daya tarik iklan, kualitas pesan iklan dan frekuensi penayangan iklan terhadap efektivitas iklan televisi produk mie instan merek Indomie Goreng Cabe Ijo. Jurnal Ekonomi Manajemen dan Bisnis, 2 (2), 424437.

Kadarisman, M. (2019). The influence of compensation, development, and supervision towards the performance of civil servants in depok city government, Indonesia, Cogent

Psychology, 6:1, DOI: $\underline{10.1080 / 23311908}$ .2019 .1620402

Lee, C., \& Hallak, R. (2018). Investigating the moderating role of education on a structural model of restaurant performance using multi-group PLS-SEM analysis. Journal of Business Research, 88, 298-305.

doi:10.1016/j.jbusres.2017.12.004

Lee, M. C. C., Idris, M. A., \& Tuckey, M. (2018). Supervisory coaching and performance feedback as mediators of the relationships between leadership styles, work engagement, and turnover intention. Human Resource Development International, 1 26. doi:10.1080/13678868.2018.1530170.

Mangkuprawira, S. (2013). Manajemen Sumber Daya Manusia Strategik, Cetakan Kedua, Ghalia Indonesia, Jakarta. 
Mor Barak, M. E., Travis, D. J., Pyun, H., \& Xie, B. (2009). The Impact of Supervision on Worker Outcomes: A Meta-analysis. Social Service Review, 83(1), 332. doi: $10.1086 / 599028$

Moser, K., \& Galais, N. (2007). SelfMonitoring and Job Performance: The moderating role of tenure. International Journal of Selection and Assessment, 15(1), 83-93. doi:10.1111/j.14682389.2007.00370.x

Muliadi., \& Amri, K. (2019). Penerimaan zakat dan penurunan kemiskinan di Aceh: Peran dan otonomi khusus sebagai pemoderasi. Jurnal Ilmiah Ekonomi Islam, 5(3), 231-244.

Ng, T. W. H., \& Feldman, D. C. (2009). How broadly does education contribute to job performance? Personnel Psychology, 62(1), 89-134. doi:10.1111/j.17446570.2008.01130.x

Orpen, C. (1994). Interactive Effects of Work Motivation and Personal Control on Employee Job Performance and Satisfaction. The Journal of Social Psychology, 134(6), 855-856. doi:10.1080/00224545.1994.9923021

Ratnawati, \& Amri, K. (2013). Pengaruh keadilan organisasional, kepercayaan pada atasan terhadap perilaku kewargaan organisasi (organizational citizenship behavior). Jurnal Ekonomi Manajemen dan Bisnis, 1(1), 56-73.

Remus, U., Wiener, M., Saunders, C., \& Mähring, M. (2020). The impact of control styles and control modes on individual-level outcomes: a first test of the integrated IS project control theory. European Journal of Information Systems, 1 19. doi:10.1080/0960085x.2020.1718008
Robescu, O., \& Iancu, A.-G. (2016). The Effects of Motivation on Employees Performance in Organizations. Valabian Journal of Economic Sciences, 7(21)' 49. 56. doi:10.1515/vjes-2016-0006

Schjoedt, L., \& Sangboon, K. (2015). Control Variables: Problematic Issues and Best Practices. The Palgrave Handbook of Research Design in Business and Management, 239-261. doi:10.1057/9781137484956_15

Segal, J. (2010). Melejitkean Kepekaan Emosional, Penerjemah Ary Nilandari, Kaifah, Bandung.

Shahzadi, I., Javed, A., Pirzada, S. S., Nasreen, S., \& Khanam, F. (2014). Impact of Employee Motivation on Employee Performance, European Journal of Business and Management, 6(23), 159-166.

Sihag, V., \& Rijsdijk, S. A. (2018). Organizational Controls and Performance Outcomes: A MetaAnalytic Assessment and Extension. Journal of Management Studies. doi:10.1111/joms.12342

Situmeang, R. R. (2017). Pengaruh pengawasan dan pengalaman kerja terhadap kinerja karyawan pada PT. Mitra Karya Anugrah, Asian Journal of Innovation and Entrepreneurship, 2(2), 148-160.

Srivastava, A. K (2008) Effect of Perceived Work Environment on Employees' Job Behaviour and Organizational Effectiveness, Journal of the Indian Academy of Applied Psychology, 34(1), 47-55.

Syamsidar, E., \& Hasyim, S. B. (2018). Pengaruh pengawasan terhadap kinerja pegawai di kantor sub unit rumah perlindungan sosial asuhan anak (RPSAA) Cisurupan - Garut, Jurnal Pembangunan dan Kebijakan Publik, 9(1), 12-20. 
Turner, A. (2017). How does intrinsic and extrinsic motivation drive performance culture in organizations? Cogent Education, 4(1). doi:10.1080/2331186x.2017.133754 3.

Uddin, M. J., Luva, R. H., \& Hossian, S. M. M. (2013). Impact of Organizational Culture on Employee Performance and Productivity: A Case Study of Telecommunication Sector in Bangladesh, International Journal of Business and Management, 8(2), 63-77.
Uno, H. (2007). Teori Motivasi dan Pengukurannya: Analisis Bidang Pendidikan, Bumi Aksara, Jakarta.

Van der Kolk, B., van Veen-Dirks, P. M. G., \& ter Bogt, H. J. (2018). The Impact of Management Control on Employee Motivation and Performance in the Public Sector. European Accounting Review,

$1-$ 28. doi:10.1080/09638180. 2018.1553728. 